\title{
ADELINA FOTÓGRAFA UNA IMAGEN PARA EL FUTURO
}

\author{
ADELINA, THE PHOTOGRAPHER \\ AN IMAGE FOR THE FUTURE
}

Carola Berenguer | carolaberenguer@outlook.es

Pilar Marchiano | marchiano.pilar@gmail.com

Mariana Moreno | moreno-mariana@hotmail.com

Facultad de Bellas Artes. Universidad Nacional de La Plata. Argentina

Recibido: 9/3/2018 | Aceptado: 12/7/2018

\section{RESUMEN}

En este trabajo se estudia una selección de imágenes fotográficas pertenecientes al fondo documental de Adelina Dematti de Alaye del Archivo Histórico de la provincia de Buenos Aires. Son fotografías que fueron tomadas por Adelina el 5 de mayo de 1984, en el partido de Ensenada, fecha en la que recuerda la desaparición de su hijo Carlos, siete años antes. Se analiza la relación entre imagen y palabra, la noción de representación y de ausencia-presencia sobre la condición ritual de la imagen a partir de la figura del desaparecido. También se trabaja el carácter público-privado y la construcción del archivo al que pertenecen las fotografías.

\section{PALABRAS CLAVE}

Archivo; Adelina Dematti de Alaye; fotografía; presenciaausencia; afiche

\section{ABSTRACT}

A selection of photographs from Adelina Dematti de Alaye's Documentary Fund of the Archivo Histórico Provincial are studied. The photographs were taken by Adelina in May 5th, 1984 in Ensenada, remembrance date of the missed of her son Carlos, seven years before. The relation between image and word, the notion of representation and presence and absence about the character of the photographs of the missed person are analysed. Also the public and private character of the photographs taken by Adelina, and the construction of her archive.

\section{KEYWORDS}

Archive; Adelina Dematti de Alaye; photography; presence-absence; poster 
Adelina Dematti de Alaye fue una de las referentes de Madres de Plaza de Mayo en la ciudad de La Plata. Se destacó dentro de este grupo por ser quien en cada ocasión registraba todos los acontecimientos, los eventos y los momentos importantes de su vida mediante su cámara fotográfica. Así fue como, desde joven, construyó un archivo personal, el cual se acrecentó profusamente a partir de la detención-desaparición de su hijo, Carlos Alaye, el 5 de mayo de 1977, durante la última dictadura cívico-militar argentina.

Andrea Giunta (2010) sostiene que la destrucción de documentos y la persecución ideológica propia del estado dictatorial generaron, en democracia, la necesidad de construir archivos que repusieran esa información. Adelina no esperó, sino que fotografió y recuperó dentro de sus posibilidades toda la información que se relacionaba con su reclamo. Es por eso que los documentos más significativos son los de esa etapa: fotografías sacadas con su cámara Kodak Fiesta, folletos, afiches, documentación y periódicos recopilados por ella misma.

Las fotografías que comenzó a capturar desde que se conformó Madres de Plaza de Mayo hasta inicios del año 2008 reinan en el archivo por ser huellas, vestigios de la búsqueda y de la denuncia constante. En ese sentido, Jorge Ribalta (2008) explica que, gracias a la fotografía, en el siglo XX ocurrió una revolución documental y un crecimiento masivo de archivos. Guardado en el garaje de su casa con cierta lógica interna de organización y registro, el archivo personal de Adelina Dematti de Alaye fue donado por ella misma en 2008 al Archivo Histórico de la provincia de Buenos Aires y se encuentra en el área de investigación de historia reciente.

A partir de entonces, se tomaron ciertas medidas organizativas para su conservación con un criterio diferente al de la autora, conformándose series y subseries temáticas y enumeradas, dispuestas en cajas adecuadas, cada una con número y año de referencia. Asimismo, se reemplazaron los álbumes plásticos en los que Adelina guardaba las fotografías, por sobres de papel libre de pH, separados por tema y año. Lo que se mantuvo, una vez institucionalizado el archivo, fue la referencia que escribía en el reverso de las fotos, que en muchos casos forma parte de la nomenclatura de las mismas. Las anotaciones y su relación con la imagen son parte constitutiva de nuestro trabajo de análisis.

Casi todas las fotografías que componen el fondo documental se encuentran digitalizadas. De esta manera, se busca prevenir problemas de deterioro - producto de la manipulación por parte de los investigadores - y alcanzar una mayor difusión de lo resguardado. Sin embargo, a pesar de los aspectos favorables que ofrece la digitalización de documentos, se nos presenta cierta disyuntiva que abordaremos de acuerdo a lo postulado por jorge Ribalta.

Según dicho autor, las fotografías digitales, como objetos en sí mismo se ven desmaterializadas. Como consecuencia, el archivo visual pierde sus características 
propias e intrínsecas: se disuelve la importancia de su impresión y el valor de su originalidad; se disocia lo escrito en su reverso y se obstruye el abordaje de la totalidad del documento. Lo que despierta una fotografía impresa no es lo mismo que una digitalizada, por ser la materialidad en sí constructora de sentido (Siracusano, 2008). No obstante, debemos reconocer que en un archivo tan grande, los trabajos y los problemas de conservación y de manejo se ven optimizados mediante esta estrategia.

Por último, como en este archivo las fotografías son centrales, hemos estructurado el trabajo en dos ejes principales. El primero se basa en un análisis visual y de contenido -ambos en relación- de nuestro recorte y objeto de estudio. El segundo trata sobre el valor de estas imágenes, sobre los documentos y los testimonios, y acerca del rol que éstas cumplen cuando se institucionalizan en el archivo.

\section{EL PODER DE LA IMAGEN}

La abundancia de documentación, la diversidad de soportes, la amplitud cronológica y nuestro interés hacia cada una de las piezas, no hicieron fácil la tarea de seleccionar un corpus a analizar. Por eso, decidimos concurrir varias veces al Archivo Provincial y establecer el tiempo de contacto con el material, con el objetivo de acercarnos a lo real y de tocarlo. Sin embargo, "por mucho que lo real parezca estar ahí, visible y aprehensible, nunca dice más que a sí mismo, y es una ingenuidad el creer que aquí se ha reducido a la esencia» (Farge, 1991, p. 14). Así, resulta importante destacar que los documentos no nos darán respuestas a menos que los interroguemos.

Un primer acercamiento hacia nuestro objeto de estudio fue la selección de fotografías tomadas por Adelina. Indagamos, principalmente, sobre aquellas que pertenecen a las décadas del setenta y del ochenta por pertenecer a los años de la última dictadura militar en la Argentina. Foto a foto, encontramos características visuales y compositivas que se repetían, como la presencia de las cabezas de las Madres con sus pañuelos blancos y, en el fondo, algún cartel referente al reclamo de aparición con vida de sus hijos [Figura 1]. La captura de momentos y de acciones concretas genera una constante de composiciones dinámicas, constituidas por direcciones que atraviesan el campo plástico y por la multiplicidad de figuras que son en su mayoría orgánicas. 


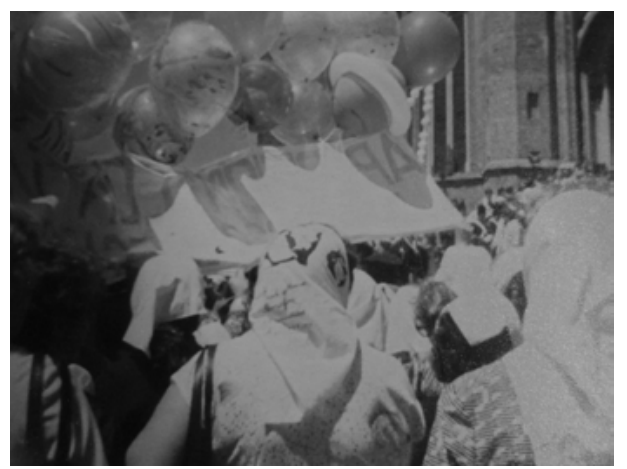

Figura 1. Foto de la serie Centenario La Plato, escrache a Bignone (1982), Adelina Dematti de Alaye. Archivo Histórico de la Provincia de Buenos Aires

Sin embargo, una serie de fotos capturó nuestra atención por el contraste con respecto a las demás: en ellas no hay personas, se trata de imágenes estáticas que, en una primera observación, no parecen documentar un hecho relacionado con la búsqueda de Carlos. A pesar de ello, solo basta adentrarse en los diferentes elementos que componen las imágenes, detenerse a analizarlos, para comprender el poder simbólico que encierran.

Son fotos de formato rectangular que pertenecen a la serie nueve-subserie ocho, albergada en la caja N. ${ }^{\circ} 3$ del archivo Adelina, la cual comprende fotografías, en su mayoría, tomadas por ella misma y datadas entre el año 1982 y el año 1992. De esta serie, seleccionamos dos imágenes que, a simple vista, presentan un paisaje urbano cotidiano de ese momento, una calle de Ensenada cuya ubicación se constata en el cartel con la señalética de dirección de partidos - Ensenada, La Plata y Punta Lara- presente en una de ellas [Figuras 2 y 2 a].
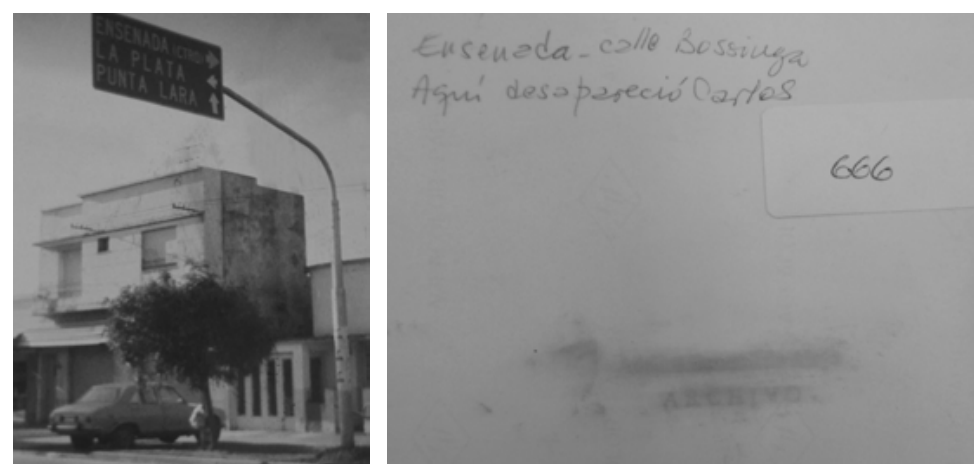

Figuras 2 y 2a. Foto de la calle Bossinga en Ensenada y recorte del reverso con la inscripción «Ensenada-calle Bossinga. Aquí desapareció Carlos» (1984), Adelina Dematti de Alaye. Archivo Histórico de la Provincia de Buenos Aires 
El contenido de esta imagen no parece ser revelador. Además del cartel, sostenido en altura por un poste, se observa una casa con las persianas bajas, un auto estacionado sobre la vereda y, a su lado, un árbol. La composición también es sencilla: predominan las líneas rectas que delimitan la mayoría de las figuras y se trazan dos diagonales principales que organizan la imagen.

Sobre la diagonal descendente se ubica el cartel, el cual dirige la mirada, no solo por tener tipografía y brindar una información concreta sobre el emplazamiento, sino por presentar un gran contraste de valor con respecto al resto de la imagen.

No obstante, la institucionalización del documento dentro del Archivo Histórico Provincial, y más específicamente en el área de investigación de historia reciente, nos indica que la imagen en sí misma dice algo más. Es desde nuestra disciplina y desde el presente que debemos indagar y cuestionar los documentos para rastrear e identificar sus significados. Paul Ricoeur (2004) los piensa como huellas, síntomas a partir de los cuales el historiador debe reconstruir la historia, interpretada desde la anacronía: «Huella, documento, pregunta forman así el trípode básico del conocimiento histórico» (p. 232). Como historiadoras de arte, entonces, debemos preguntarle a la imagen, la cual es constructora de sentidos.

El cartel como acento en la imagen es el que nos da la respuesta, ya que si dirigimos la mirada al poste que lo sostiene, encontramos afiches impresos en blanco y negro pegados sobre él. En otra de las fotografías [Figura 3], Adelina los capturó en un primer plano, pudiéndose identificar el retrato de un hombre joven y un pie de foto escrito en letra imprenta mayúscula que indica el nombre, «Carlos E. Alaye», y debajo, en menor tamaño, «desaparecido el 5-5-77». Los afiches en blanco y negro envueltos en el poste, pasan a ser el centro de atención en nuestra investigación.

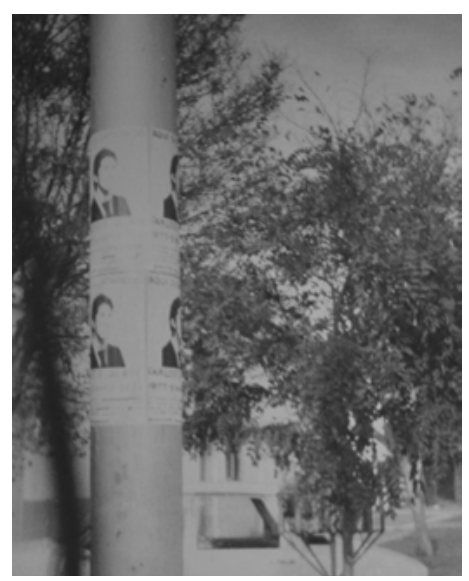

Figura 3. Afiches con el retrato de Carlos pegados a un poste (1984), Adelina Dematti de Alaye. Archivo Histórico de la Provincia de Buenos Aires 
Este afiche no es el único que comprende una foto carnet ampliada, un nombre y un apellido, junto con una fecha y la palabra desaparecido. Este dispositivo adquirió un lugar central, tanto en dictadura como en democracia, en la búsqueda de los detenidos-desaparecidos y en el reclamo de memoria, verdad y justicia. Fueron, y aún son, característicos en las marchas, escraches y en las rondas de las Madres de Plaza de Mayo, donde se vuelven presencia de los ausentes

Adelina utilizó ese mismo retrato para sus pancartas, que llevaba consigo cada vez que alzaba su brazo en reclamo de su hijo, dato que pudimos constatar indagando en el resto del archivo [Figura 4].

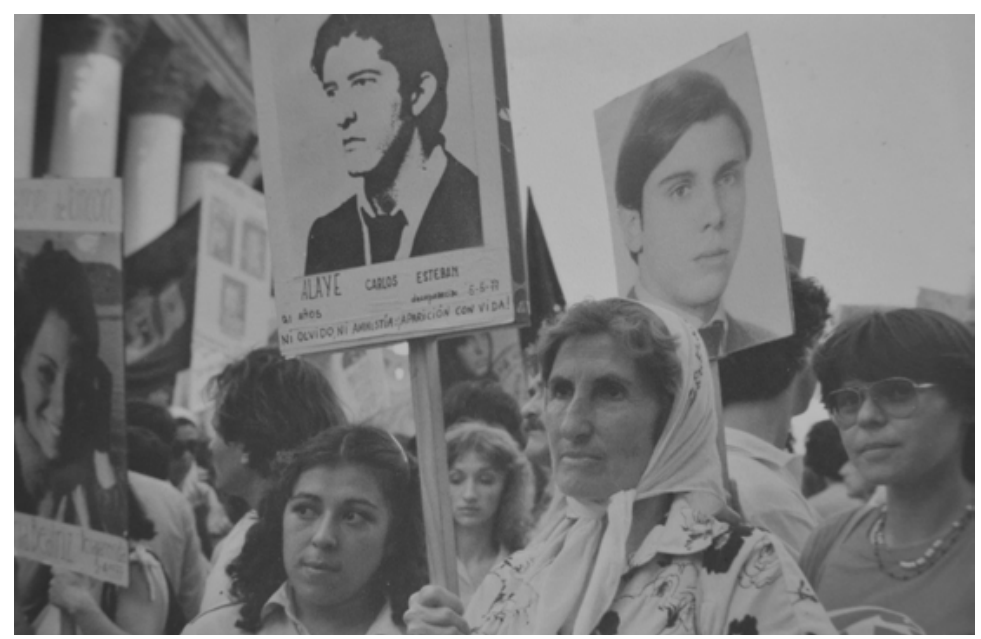

Figura 4. Último jueves de la dictadura (1983), Pose-Alaye. Archivo Histórico de la Provincia de Buenos Aires

El retrato de Carlos en los afiches genera la ilusión de que aquella ausencia se hace presente. Se trata de una ausencia en la representación o de su dimensión transparente o transitiva (Marin, 1992), es decir, la imagen vuelve a traer algo que está ausente, algo que no está. En convivencia con esta dimensión, se encuentra su complemento: la dimensión opaca o reflexiva, que se expresa en la materialidad del afiche ya que se presenta representando algo.

La primera fotografía analizada [Figura 2], en la que el afiche se ubica en el poste de la señalización vial, tiene un impacto mayor cuando la volteamos y leemos la frase que Adelina escribió con lapicera: «Ensenada-calle Bossinga. Aquí desapareció Carlos». A lo cual se le suma que fue tomada el día 5 de mayo de 1984, a siete años de la detención-desaparición de su hijo. Esta inscripción reconfigura la manera de analizar la imagen: el foco ya no está puesto solo en el 
afiche sino en su emplazamiento. Su ubicación en el poste del cartel que explicita la dirección de la calle donde desapareció Carlos Alaye, confirma y denuncia su detención y desaparición.

En este sentido, se presenta cierta disyuntiva entre la presencia-ausencia y la dimensión opaca-transparente de la imagen. Mientras que en los afiches ubicados en el poste predomina la dimensión transparente, en el total de la fotografía Adelina manipula de manera intencionada los elementos de la imagen con el fin de enunciar un mensaje, lo cual hace que prevalezca la opacidad por sobre la transparencia. La materialidad del afiche, el poste y el cartel funcionan a modo de señalamiento: «Aquí desapareció Carlos».

\section{LA FUNCIÓN DEL AFICHE}

La práctica de familiares y amigos de pegar los afiches en las calles con la fotografía carnet ampliada y fotocopiada fue, en un inicio, la respuesta directa a la búsqueda de personas. Es una de las primeras acciones llevadas a cabo por las Madres, incluso antes de la utilización del pañuelo y de las marchas: el uso de una foto extraída de un álbum familiar o, sobre todo, de un documento de identidad, era esencial para poder averiguar algún dato sobre la desaparición. Recorrer hospitales, morgues o comisarías con las imágenes y pegarlas en el espacio público. Ana Longoni (2010) comenta lo siguiente sobre esta práctica:

[... es un gesto que sin duda está vinculado con cualquier búsqueda del paradero de un ausente, de un ausentado y que luego a partir del año 77-78, cuando las madres empiezan a conformarse como organismo, adquirió primero una cierta materialización a partir de estas pequeñas pancartas que las madres colgaban de su cuerpo, o abrochaban sobre su ropa con alfileres de gancho y que siempre tenían que ver con el vínculo que unía a esa persona con la persona representada en esa fotografía, es decir, hacían hincapié fundamentalmente en el vínculo de unión, en el vínculo familiar que unía a la persona representada en la fotografía con la persona que portaba la fotografía (p. 3).

Con la consolidación del movimiento de Madres de Plaza de Mayo, las acciones individuales comienzan a ser colectivas y eso se manifiesta, siguiendo a Longoni (2010), en la utilización de la misma foto pero con un texto que contiene fechas, lugares de desaparición o la palabra «desaparecido». Podemos rastrear este recurso en la fotografía que Adelina capturó de una pared intervenida del edificio Pasaje Dardo Rocha de la Ciudad de La Plata [Figura 5]. La misma contiene un 
collage que está compuesto, en parte, por imágenes de desaparecidos, entre ellas, la foto de Carlos, con la palabra «desaparecido» y la fecha.

El afiche como dispositivo de búsqueda y de reclamo por la aparición con vida, también se complementa con su función conmemorativa, como es el caso de las fotografías tomadas el 5 de mayo de 1984, que constituyen nuestro principal recorte de análisis. Adelina fue el mismo día de la desaparición de Carlos al lugar donde lo secuestraron, pegó el afiche con el retrato de su hijo en el poste de la señalización vial y fotografió la escena: una imagen desolada que refuerza su carácter conmemorativo.

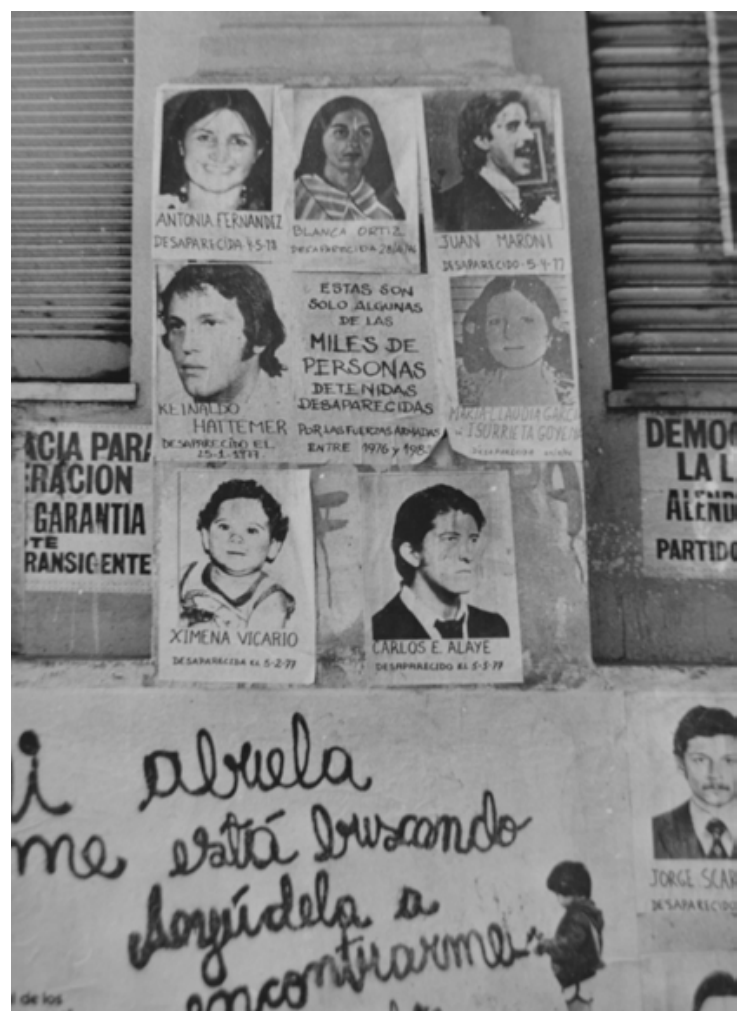

Figura 5. Fotografía de la pared del Pasaje Dardo Rocha, La Plata (1984). Archivo Histórico de la Provincia de Buenos Aires

Dentro de un cuerpo de fotos donde la presencia de la multitud de personas en marchas, manifestaciones de todo tipo, misas y viajes es un denominador común, estas imágenes parecen responder a un momento íntimo de Adelina. 


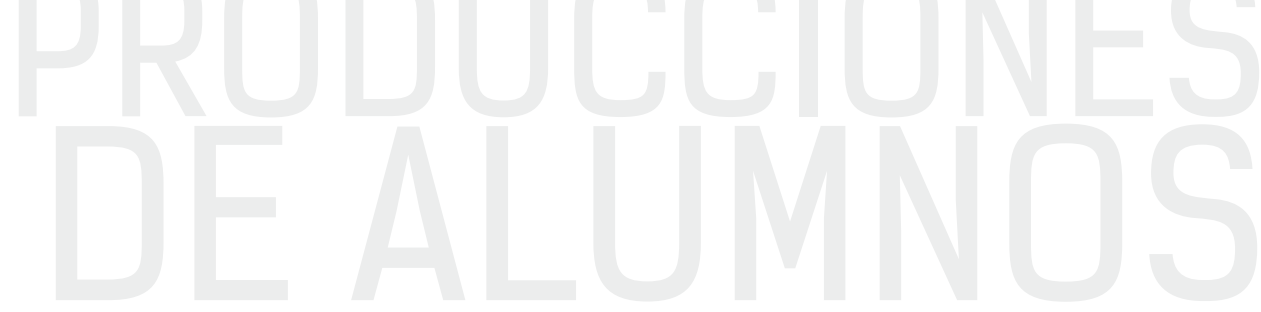

Fotografía una calle, un afiche, como prueba de su paso por ese lugar el día que se cumple el séptimo aniversario de la desaparición de Carlos. Ante la desaparición, «la fotografía ha podido funcionar como soporte sustituto de un duelo imposible» (Blejmar y otros, 2013, p. 17).

Este duelo que permite la fotografía, no deja de lado su función primera que aún posee en las luchas y en los reclamos por la reivindicación de los detenidos-desaparecidos: la búsqueda de una persona y el deseo de aparición de la misma. Adelina dejó testimonio de ello al opinar sobre su propio archivo: «en un primer momento, era para mostrárselo a Carlos cuando volviera; luego, para poder contar la historia familiar a mis nietos; hoy creo que siempre fue para el futuro» (Clarke y otros, 2010).

\section{LA FOTOGRAFÍA COMO DOCUMENTO}

En un comienzo, Adelina recopilaba documentación en relación con la detención y la desaparición de Carlos, para que, cuando él volviera, viera todo lo que había hecho en su ausencia. Sin embargo, también tenía presentes las funciones potenciales del archivo, ya que tenía la intención de que este trascendiera y sirviera al futuro. En este mismo sentido, podemos destacar la cuestión del porvenir, de servir como una respuesta, una promesa y una responsabilidad para el mañana (Derrida, 1996).

En el fondo documental de Adelina Dematti de Alaye existe una relación compleja en la definición de archivo personal-privado y colectivo-privado, ya que, a pesar de ser el compendio de documentos que Adelina guardaba en su garaje, el archivo se conserva para la historia Argentina como testimonio de una testigo y víctima del horror. Aunque el acto de donarlo fue voluntario, el domiciliar el archivo en la institución -o según Jacques Derrida, el asignarle una residencia al archivo- contribuye a la memoria pública y a la historia colectiva, lo que marca el paso de lo privado a lo público.

El área de investigación de historia reciente y la incorporación del Archivo de Adelina fueron parte de un cambio de paradigma institucional del Archivo Histórico Provincial, el cual abrió el debate acerca del límite entre historia y memoria, que se dio gracias a las políticas públicas impulsadas a partir del año 2003. La inclusión de la memoria es un indicio de cómo el archivo - junto con la institución - se encuentra atravesado por las políticas del momento, en estrecha relación con el tiempo presente. Este intercambio constante entre pasado, presente y también futuro nos acerca al concepto de discontinuidad que propone Michael Foucault (1979): la historia no es una sucesión de hechos progresivos sino que se constituye a modo de trama en la que la linealidad se quiebra a partir de los acontecimientos, que crean sus propios antecedentes históricos. Es así, que 


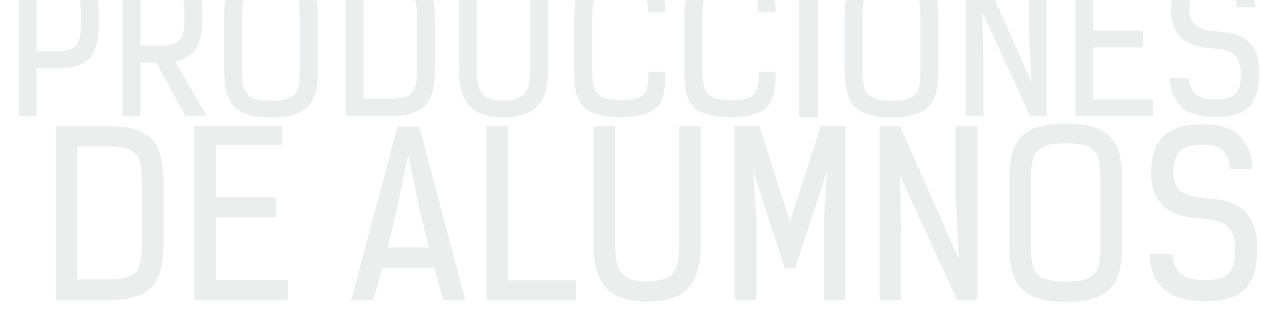

el historiador siempre está en discontinuidad con el archivo ya que recurre a ese pasado desde el presente.

En síntesis, podemos hablar del archivo de Adelina Dematti de Alaye como el testimonio de un acontecimiento, una memoria declarada y una prueba documental -en términos de Ricoeur (2004) - que a través de su materialidad y como archivo visual, adquiere un valor inigualable como productor de significantes y significados.

\section{LA OBRA Y EL ARCHIVO}

La donación del trabajo realizado a lo largo de toda su vida se puede considerar como un acto de conciencia histórica y social. Su lucha y su búsqueda como madre han quedado plasmadas en cada documento, papel y fotografía que conforman este archivo, el cual hoy, gracias a ella, es de acceso público. El acercamiento al archivo, entonces, se puede producir desde distintos lugares y posiciones, entre otros: como pruebas de la desaparición de personas y de delitos de lesa humanidad -como ha sido el caso del esclarecimiento de las inhumaciones en el cementerio de La Plata-; para encontrar datos en relación con la identidad de las personas desaparecidas; y también, para abordarlo desde trabajos de investigación que puedan considerar el material desde una perspectiva histórica.

Como estudiosas de lo visual, nos resulta significativo que la autora fuera Madre de Plaza de Mayo y, a la vez, fotógrafa. Por eso, nuestra aproximación al archivo de Adelina se centra en las imágenes y en la historia que representan. Así también, proponemos un abordaje que contemple la mirada de Adelina y su producción desde lo artístico. Las fotografías que integran el archivo, un total de mil doscientas, tienen la característica de pertenecer a esta mirada particular de Adelina como actora dentro del grupo de Madres y, por lo tanto, como testigo y víctima de muchos acontecimientos relacionados con la dictadura y la desaparición forzada de personas. Este punto de vista interno e íntimo, generalmente, es visto desde su carácter documental; sin embargo, enfatizamos el valor material como prueba de los acontecimientos y la imagen, como productora de sentidos que tiene en cuenta, a la vez, la relación que se establece con la palabra.

Cuando hablamos de Adelina fotógrafa, nos referimos a una mujer que pasó años de su vida capturando momentos significativos y adquiriendo cierto nivel en sus producciones, las cuales merecen ser tomadas como tales. De esta manera, esperamos contribuir a la potencialización de nuevas lecturas e interrogantes hacia su fotografía, considerada como un elemento artístico. 


\section{REFERENCIAS}

Blejmar, J.; Fortuny, N.; García, L. (2013). Introducción. En Instontóneos de la memoria: fotografía y dictodura en Argentino y Américo Lotino (pp. 9-21). Buenos Aires, Argentina: Libraria.

Chartier, R. (1994). El mundo como representación. En El mundo como representoción. Estudios sobre historia cultural (pp. 45-61). Barcelona, España: Gedisa.

Clarke, G.; Lloret, F.; Sarno, A. (2010). Los martes Adelino. Resignificación de documentos escritos a partir de testimonios orales. Tercer encuentro Bonaerense de Memoria e Historia Oral, Morón, Argentina.

Dematti de Alaye, A. (mayo de 1984). Afiches con el retrato de Carlos pegados a un poste [Fotografía]. Archivo personal de Adelina Dematti de Alaye (N. ${ }^{\circ}$ inv. 667). Archivo Histórico de la provincia de Buenos Aires.

Dematti de Alaye, A. (mayo de 1984). Calle Bossinga en Ensenada [Fotografía]. Archivo personal de Adelina Dematti de Alaye (N. inv. 666). Archivo Histórico de la provincia de Buenos Aires.

Dematti de Alaye, A. (noviembre de 1982). Escrache a Bignone [Fotografía]. Archivo personal de Adelina Dematti de Alaye (N. inv. 1837). Archivo Histórico de la provincia de Buenos Aires.

Dematti de Alaye, A. (abril de 1984). Pared del Pasaje Dardo Rocha, La Plata [Fotografía]. Archivo personal de Adelina Dematti de Alaye (N. inv. 1502). Archivo Histórico de la provincia de Buenos Aires.

Dematti de Alaye, A. (diciembre de 1983). Último jueves de la dictadura [Fotografía]. Archivo personal de Adelina Dematti de Alaye (N. inv. 1626). Archivo Histórico de la provincia de Buenos Aires.

Derrida, J. (1996). Mal de archivo. Una impresión freudiona. Madrid, España: Trotta.

Farge, A. (1991). La atracción del archivo. Valencia, España: Edicions Alfons El Magnánim. Institución Valenciana de Estudios e Investigación.

Foucault, M. (1979). La arqueología del saber. Ciudad de México, México: Siglo veintiuno editores. 
Giunta, A. (2010). Archivos. Políticas del conocimiento en el arte de América Latina. ERRATA. Revisto de Artes Visuales, (1), 20-37. Recuperado de https:// issuu.com/revistaerrata/docs/revista_de_artes_visuales_errata_1_issuu

Longoni, A. (2010). Arte y Política. Políticas visuales del movimiento de derechos humanos desde la última dictadura: fotos, siluetas y escraches. Aletheia, 1 (1), 1-23. Recuperado de http://www.aletheia.fahce.unlp.edu.ar/numeros/ numero-1/pdfs/Longoni-\%20Aletheia\%20vol\%201.\%20n1.pdf

Marin, L. (1992). El cuerpo de poder y la encarnación en Port Royal y Pascal o de la «figurabilidad» del absoluto político. En M. Feher, R. Naddaff y N. Tazi (Eds.), Fragmentos para una historia del cuerpo humano. T. III. (pp. 421-447). Madrid, España: Taurus.

Ribalta, J. (2008). Archivo Universal. La condición del documento y la utopía fotográfica moderna. Barcelona, España: MACBA.

Ricoeur, P. (2004). Fase documental. La memoria archivada. El tiempo histórico. En La memoria, la historia y el olvido (pp. 198-236). Buenos Aires, Argentina: Fondo de Cultura Económica.

Siracusano, G. (2008). Las entrañas del arte. Un relato material (S. XVII -XIX). Buenos Aires, Argentina: Fundación Osde. 